\title{
Perancangan Informasi Budaya Mantra Rahasia Jawa Kuno Melalui Media Buku Ilustrasi
}

\author{
Deby Nur Muhamad Ghazali ${ }^{1}$, Kankan Kasmana ${ }^{2}$ \\ ${ }^{I}$ Desain Komunikasi Visual, Fakultas Desain, Universitas Komputer Indonesia, Bandung \\ ${ }^{2}$ Magister Desain, Fakultas Desain, Universitas Komputer Indonesia, Bandung \\ Email: ${ }^{1}$ debycloud0208@gmail.com, ${ }^{2}$ kankan.kasmana@email.unikom.ac.id
}

\begin{abstract}
Abstrak: Mantra rahasia Jawa kuno merupakan mantra yang secara rahasia diturunkan secara turun-temurun dari jaman nenek moyang hingga sekarang. Pembacaan dan tata cara pengamalan mantra sangat unik, oleh sebab itu mantra rahasia menjadi tutur budaya orang Jawa. Saking melekatnya dan saling berkaitannya antara mantra dan orang Jawa, maka jika dikaitkan pada kepercayaan sebuah agama mantra merupakan kegiatan yang menjurus pada keburukan dan syirik. Tetapi meski begitu bait-bait yang terkandung pada mantra adalah sebuah seni juga adat istiadat yang kuat. Mantra rahasia baik atau buruk bergantung pada pembaca mantra itu sendiri, baik dalam niat maupun maksud serta tujuan membacakan mantra rahasia.
\end{abstract}

Kata kunci: budaya leluhur, Jawa, mantra rahasia.

Abstract: The secret mantra of ancient Java is a mantra that was secretly passed down from generation to generation until now. The recitation and procedures for practicing the mantra are very unique, therefore the secret mantra becomes the Javanese culture's speech. Because of the inherent and interrelated between the mantra and the Javanese, if it is associated with the belief of a religious mantra is an activity that leads to evil and shirk. But even so the stanzas contained in mantras are an art as well as strong customs. Secret spells good or bad depends on the spell reader itself, both in intention and intent and purpose of reciting secret spells.

Keywords: ancestral culture, Java, secret mantra. 


\section{PENDAHULUAN}

Menurut Alistjahbana (1952), mantra adalah susunan kata atau kalimat khusus yang isinya mengandung kekuatan gaib, dan susunan kata berisi puisi dengan memiliki rima dan irama. Biasanya mantra ini sering digunakan oleh dukun, atau pawang untuk menandingi kekuatan ghaib. Persamaan mantra dalam bahasa melayu adalah jampi, serpah, tawar, sembur, cuca, puja, seru dan tangkal. Ciri khusus yang membedakan antara mantra dengan puisi yaitu sifatnya yang esoferik (bahasa khusus pembicara dengan lawan bicara yang misterius). Mantra dijadikan sebagai budaya yang ada sejak jaman dahulu (jaman nenek moyang). Mantra ini digolongkan ke dalam golongan bahasa berirama, sedangkan bahasa berirama ini termasuk jenis puisi lama. Dalam bahasa berirama itu, irama bahasa sangat dipentingkan, terutama dalam mantra diutamakan sekali irama yang kuat dan teratur untuk membangkitkan tenaga gaib.

Ciri-ciri mantra ialah terdiri atas beberapa rangkaian kata yang memiliki irama, isi dari mantra berhubungan dengan kekuatan ghaib, yang isi konsepnya menggambarkan kepercayaan suatu masyarakat pada saat itu, mantra dibuat dan diamalkan untuk tujuan tertentu. Mantra didapat secara ghaib seperti diwarisi dari perguruan yang diikuti, mantra juga mengandung rayuan dan perintah, di dalam mantra terdapat kecenderungan esoterik atau khusus pada setiap kata-katanya, mantra mementingkan keindahan permainan bunyi.

Riyono (2009) berpendapat, bahwa pada intinya fungsi dari mantra yang masyarakat Jawa lestarikan dan gunakan adalah bentuk penghormatan pada leluhur atau nenek moyang, dan memohon keberkahan di setiap harinya. Semisal, meminta berkah atas hasil panen agar berlimpah, meminta berkah atas rezeki yang didapat, dan memohon berkah atas bumi yang ditinggali. Di Indonesia, banyak sekali daerah-daerah yang masih menggunakan mantra sebagai bagian dari budaya juga adat istiadat. Ada yang digunakan pada upacara kematian, upacara pernikahan, dan ada pula pada upacara keagamaan. Berikut merupakan beberapa daerah yang masih menggunakan mantra yaitu; Tanah Toraja, Kota Barus (Kabupaten Tapanuli Tengah), Banten, Kalimantan, Sumatera, Kepulauan Riau, Jawa Barat, Jawa Timur, Jawa Tengah.

Menurut Herususanto (2008), hal tersebut secara sederhana memaparkan dengan jelas, dan dapat dimengerti secara tepat meski oleh orang awam. Dapat dikatakan hal tersebut sudah mencerminkan keseluruhan dasar konsep berpikir orang Jawa, yang menunjukkan bahwa perasaan memegang peranan utama di samping jiwa dan akal yang disebut cipta, rasa, dan karsa.

Menurut Wijoyo (2019), mengenai mantra yang kuat dan kental dengan budaya leluhur, maka pembacaan mantra pun menggunakan sebuah aturan. Tata cara (ritual) membacakan mantra untuk leluhur yaitu, seperti tempat dibacakannya mantra tersebut, waktu yang tepat menurut hitungan Jawa kuno, menyiapkan sesajen yang diharuskan mengikuti arahan juru kunci, lalu untuk harinya disesuaikan menurut hitungan Jawa, untuk membacakan mantra tersebut. Bahkan sebelum dilafalkannya mantra tersebut, dukun atau cenayang dan pembaca 
diwajibkan untuk berpuasa dengan hari dan lamanya waktu berpuasa yang berbeda tergantung dari mantra yang dibacakan. Setelah dibacakannya mantra rahasia, masyarakat meyakini bahwa dukun atau cenayang dan pembaca mantra tersebut dibawa ke alam gaib, berdiskusi demi mendapat kesepakatan atas sesumpah atau pepujian yang diinginkan untuk dikabulkan. Jika seluruh aturan dijalankan dengan sesuai maka tinggal menunggu hasilnya saja, akan tetapi jika di dalam hati tercipta niat buruk dan keinginan lain maka meski melakukan tata cara dengan benar hasilnya akan menjadi keburukan bagi si pembaca yang bisa berupa kutukan, cacat mental (gila), juga bisa sampai menghilangkan nyawa.

\section{METODE}

Menurut Morrisey (2011), strategi merupakan proses untuk menentukan arah yang dituju. Dalam perancangan ini digunakan strategi perancangan dengan dibantu pengumpulan data sebelumnya terdapat masalah pada pandangan budaya adat istiadat yang ada di Jawa, maka masyarakat khususnya remaja dana dewasa secara umum membutuhkan sebuah media yang bersifat naratif dan mudah didapatkan untuk menumbuhkan kembali budaya kebiasaan membaca namun dengan bantuan tambahan dari gambar ilustrasi, sehingga diharapkan cara tersebut dapat semakin menarik minat baca dari khalayak sasaran untuk membaca buku Mantra Rahasia Jawa Kuno, yang berfungsi sebagai sarana informasi serta penyampaian hal-hal unik yang ada di Jawa yang sudah dituangkan semua dalam buku Mantra Rahasia Jawa Kuno.

\section{Objek Penelitian}

Menurut Riduwan (2004), studi observasi merupakan bagian dari penguat sumber dan juga pengangkatan perancangan agar lebih akurat dan terpercaya, dalam hal ini penulis melakukan observasi langsung ke kota Yogjakarta dan melakukan penelitian di Museum Kareta Keraton Ngayogyakarta, Museum Sonobudoyo, Keraton, dan Badan Pelestarian Cagar Budaya Jawa Tengah.

\section{Prosedur Pengambilan Data}

Prosedur pengambilan data menggunakan metode wawancara langsung, tujuan wawancara secara umum adalah untuk mendapatkan informasi yang akurat dari narasumber dengan menyampaikan beberapa pertanyaan tertentu kepada narasumber. Secara khusus, menggali dan mendapatkan informasi atau data dari orang pertama (primer), untuk melengkapi informasi/data yang dikumpulkan dari teknik pengumpulan data lainnya dan untuk mendapatkan konfirmasi dengan menguji hasil pengumpulan data lainnya. 
Setelah proses observasi dan pengamatan yang didasari oleh fakta dari sejarah peninggalan Jawa, cerita rakyat Jawa serta acuan terhadap kaidah budaya yang ada, langkah selanjutnya adalah proses wawancara. Ada dua subjek wawancara yang menjadi fokus dalam penelitian ini, yaitu sejarahwan dan pelaku yang melakukan mantra rahasia yang berlokasi di Jawa Tengah tepatnya Daerah Istimewa Yogyakarta. Dua subjek wawancara ini dipilih karena merupakan subjek sekaligus sumber dari tujuan perancangan yang terdapat pada inti budaya Mantra Rahasia Jawa Kuno.

\section{Tahapan Pembedahan Objek Penelitian}

Data dan fakta yang penulis dapat dari hasil wawancara terhadap sejarahwan di Badan Pelestarian Cagar Budaya Jawa Tengah dan seorang Abdi Dalem dari Museum Kareta Ngayogyakarta.

Menurut Agus Widiatmoko, Ss. Setelah melakukan beberapa penelitian di candi ataupun prasasti tidak ditulis mantra, tapi mantra ada di kitab-kitab. Penggunaan mantra dipercaya pertama kali sejak masa sebelum Hindhu-Budha, namun karena Hindu-Budha menggunakan mantra dalam pembacaan do'a untuk Dewa-Dewa maka dari sejak itulah mantra digunakan oleh leluhur. Sejarah Jawa banyak yang disembunyikan, itu karena ada banyak hal sejarah Jawa kuno yang tidak meninggalkan bukti fisik sehingga tidak bisa dibuktikan keasliannya. Namun, jika dikaitkan pada keadaan bisa saja sejarah mengenai mantra benar adanya. Karena, contoh semisal pembangunan sebuah candi setelah dipikirkan menggunakan akal sehat maka sangat mustahil candi berdiri kokoh tanpa adanya bantuan semen sebagai perekat untuk menyatukan antara batu-batu. Kemudian letak candi harus ditentukan oleh cenayang/pendeta/juru kunci kerajaan, dengan maksud arti tempat tersebut yang berbeda-beda.

Tapi jika dikaitkan pada sejarah yang berbicara bahwa candi dibangun oleh arsitek dengan maksud sebagai bangun untuk beribadah atau berdo'a dengan mengandung unsur seni yang tinggi, masyarakat justru mempercayai bahwa bangunan candi dibuat secara ajaib sebagai peninggalan leluhur, yang kini dijadikan tempat untuk menghormati Raja-raja. Bangunan candi dibangun dengan mengkhiblat pada gunung berapi dengan arti saat juru kunci kerajaan membacakan mantra kesuburan, kemakmuran, kesejahteraan dan kebahagiaan maka mantra tersebut dapat langsung didengar dan terkabulkan. Contohnya adalah lingkungan sekitar candi, gununggunung bahkan kota sekalipun tidak pernah kekurangan air, karena jika diibaratkan air adalah sumber kehidupan dan juga air merupakan pusat utama pembacaan mantra pada jaman Jawa Kuno sebelum mengenal menyiapkan sesaji/sesajen atau ritual persembahan lainnya. Sangat sulit agar tidak simpang siur atas sejarah Jawa Kuno karena bukti-bukti atau peninggalannya benar-benar tidak bisa ditemukan, bahkan beberapa kerajaan Jawa tidak meninggalkan sejarah sama sekali dimulai dari bangunan kerjaan hingga benda-benda pusaka pada masa kejayaan kerajaan tersebut. Hanya bukti-bukti peninggalan nenek moyang berupa kebiasaan saja yaitu, masyarakat Jawa harus selalu hidup berdampingan dengan beragam agama, 
beragam suku, dan juga adat istiadat kebiasaan, namun tetap hidup damai. Adat kebiasaan tersebut kini menjadi budaya yang diturunkan leluhur berupa kebiasaan menghormati dan ramah tamah juga bersaudara dengan siapa pun menjadikan Jawa khususnya Jawa Tengah menjadi kota yang damai dan tentram.

Menurut Muhamad Wijoyo, keraton Ngayogyakarta ini adalah kerajaan Kejawen maka dari itu penggunaan mantra sudah pasti tetap dan akan terus dilakukan oleh seluruh kejawen terutama keluarga kerajaan dengan peninggalan sejarah kuno berupa mantra rahasia dan juga benda-benda pusakanya. Karena namanya mantra rahasia maka akan selalu menjadi rahasia bahwa tidak bisa sembarangan tahu tanpa mendapat ijin atau perintah langsung dari keraton. Seorang abdi dalem saja tidak akan memberitahukannya karena hal tersebut ditutup rapat. Contoh buktinya adalah kehidupan abdi ndalem yang dimantrai sebuah mantra rahasia agar kehidupannya sejahtera, makmur, sehat dan diberkahi. Maka meski mendapatkan gaji Rp. 27.500, saja hidup abdi dalem tidak pernah kekurangan bahkan anak Bapak Muhammad Wijoyo kini adalah seorang sarjana yang dibiayai dari gaji yang diberikan keraton tersebut. Contoh bukti lainnya adalah kareta keraton yang berumur 286 tahun, sedangkan umur tanah Jawa saja baru 250 tahun, kareta itu tidak pernah rusak dan selalu kokoh karena pada penopangnya diberi mantra rahasia oleh juru kunci keraton. Kemudian pelestarian lainnya adalah memberikan sesajen/sesaji setiap malam Jum'at terutama Jum'at kliwon dan malam satu Suro. Lalu terakhir adalah pemandian kareta keraton menggunakan mawar merah di pagi hari setelah peringatan malam satu Suro dengan waktu yang ditentukan yaitu pukul 6-9 pagi.

\section{Metode Analisa}

Metode analisa dalam menyelesaikan kasus mengenai mantra rahasia Jawa kuno, yaitu mencari pemecahan mengenai penggunaan, tata cara, dan pelestarian mantra rahasia yang masih digunakan sampai saat ini.

\section{Target Audiens}

Unsur khalayak adalah berhasil tidaknya proses komunikasi sangat ditentukan oleh khalayak. Maka dari itu jika kegiatan komunikasi tidak berjalan lancar jika khalayak tidak satu juan dalam mencapai tujuan yang diinginkan. Sedangkan sasaran adalah sesuatu yang menjadi tujuan dan yang menjadi skala prioritas dalam sebuah perancangan. Jadi khalayak sasaran pada perancangan ini berdasarkan segi demografis, psikografis dan geografis.

Usia 17-60 tahun, masa yang mencakup dua bagian yaitu remaja dan juga dewasa, hingga lanjut usia. Dengan jenis kelamin Pria dan Wanita. Pendidikan dari SMA hingga Karyawan/Pensiunan. Yang secara psikografis masa tersebut merupakan masa dimana individu sudah dapat menentukan mana yang baik juga mana yang buruk. Sedangkan secara geografis, target audiens yang bertempat tinggal di beberapa Kota besar yang ada di Indonesia. 


\section{Strategi Komunikasi}

1) Strategi Komunikasi Verbal

Dalam perancangan informasi ini bahasa yang digunakan dalam pendekatan verbal yaitu menggunakan bahasa Indonesia dan Jawa kuno. Penggunaan bahasa Indonesia karena khalayak sasaran mayoritas menggunakan bahasa Indonesia. Sedangkan bahasa Jawa karena mantra rahasia berkaitan dengan bahasa Jawa sehingga tidak dapat dilepaskan.

2) Strategi Komunikasi Visual

Pendekatan visual yang dibuat dalam perancangan ini menggunakan ilustrasi berupa gambar digital sebagai penguat penjelasan-penjelasan dari buku ilustrasi. Ilustrasi yang digunakan mengacu pada gaya Jawa kuno. Bentuk ilustrasi yang digunakan adalah bertema dark art dan gambar surealis, lalu penggunaan latar semakin memperkuat pesan yang ingin disampaikan.

Pemilihan tema dark art dikarenakan berhubungan dengan mistis, sehingga nuansa misteri yang diangkat lebih dalam sampai pada khalayak sasaran. Sedangkan pemilihan tema surealis yang bersifat esoteris, karena media yang akan dibuat masih bersifat esoteris yang kebenarannya masih banyak yang tidak mempercayai.

\section{Tujuan dan Pendekatan Komunikasi}

Tujuan dari komunikasi adalah memberikan informasi secara luas mengenai budaya Jawa dengan menggunakan mantra rahasia yang memiliki kekuatan supranatural dan nilai-nilai budaya turun temurun yang kini menjadi warisan nenek moyang. Sehingga masyarakat khususnya khalayak sasaran yang dapat memilah baik buruknya suatu hal yang diharapkan dapat membuang sisi negatif dan mengambil sisi positif demi melestarikan budaya bangsa Indonesia.

\section{Mandatory}

Menurut Pann (2019), mandatory adalah perusahaan atau lembaga yang memberikan mandat, berdasarkan dari perancangan yang dibuat maka mandatory dari perancangan buku ilustrasi Mantra Rahasia Jawa Kuno adalah Narasi.

Penerbit Narasi merupakan lini penerbit dari salah satu wadah besar PT. Media Pressindo Group. Penerbitan lini ini adalah untuk pengkategorian tema. Dimana penerbit Narasi mengambil porsi tema di wilayah sosial-politik, sosial-budaya, fiksi, sejarah, buku-buku babon (manuskrip, naskah-naskah). 


\section{Strategi Kreatif dan Media}

Untuk strategi kreatif dalam perancangan adalah membuat buku informasi yang dikemas dengan bantuan gambar ilustrasi agar lebih menarik minat pembaca. Kemudian agar dapat memperkuat suatu keadaan dan ciri khas dari jati diri orang Jawa kuno melalui pemilihan warna gelap, dengan pengambilan warna tersebut bermaksud agar misteri yang dikuak bisa tersampaikan pada khalayak pembaca.

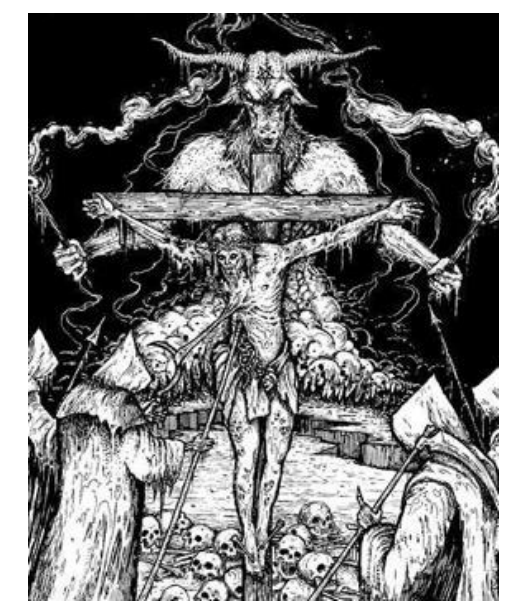

Gambar 1. Referensi Komunikasi Visual Sumber: https://id.pinterest.com/pin/781093129107403804/ (diakses pada: 10 Desember 2019)

\section{Copywriting}

"Mantra merupakan bagian dari budaya leluhur". Dengan pertimbangan tanpa menghilangkan sisi adat istiadat yang dibahas, dan tetap berpegang untuk mengangkat budaya leluhur Jawa kuno agar lebih diketahui khalayak banyak.

\section{Rancangan Visual}

Gaya visual akan disesuaikan dengan isi dalam buku ilustrasi dengan melihat pada khalayak sasaran, dengan membuat bentuk-bentuk dan ciri khas dari materi yang diangkat. Kemudian dikembangkan dengan bentuk visual yang lebih inovatif untuk kalangan remaja maupun dewasa. Konsep visual digambarkan khususnya pada mantra rahasia dan beberapa tokoh Jawa. Konsep visual dark art dalam buku ilustrasi Mantra Rahasia Jawa Kuno sebagai penegasan tema agar kesan mistis yang diharapkan akan keluar pada ilustrasinya.

Menurut Akh3ru (2012), dark art merupakan gaya seni yang didefinisikan sebagai perubahan suasana menjadi "gelap" atau bersifat horor dan misterius. Gaya seni ini merupakan produk dari abad ke-20. 
Menurut Kasmana (2009), dark art diambil sebagai identitas dari misteri yang singkat dan menguatkan segala sesuatu mengenai mantra. Selain itu dark art sendiri merupakan ciri atau identitas penulis yang dalam setiap ilustrasinya, sering kali menggunakan tema tersebut. Identitas dibangun oleh sesuatu yang khas yang muncul pada diri seseorang, yang muncul dalam sebuah relasi sosial. Identitas seseorang dibangun oleh berbagai macam faktor selera dan cita rasa adalah salah satunya.

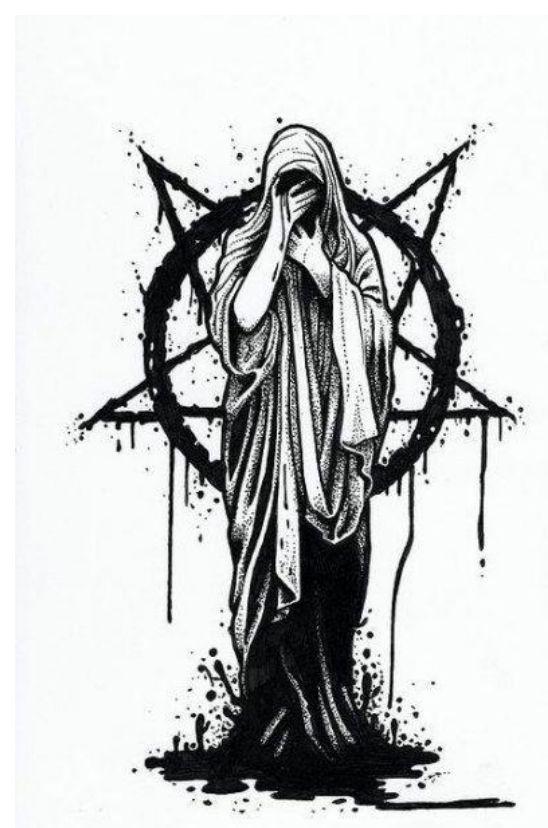

Gambar 2. Referensi Visual Ilustrasi Dark Art Sumber: https://id.pinterest.com/pin/820288519614923803/

(diakses pada: 3 Januari 2020)

\section{HASIL DAN PEMBAHASAN}

\section{Format Desain}

Menurut Kurniawan (2009), desain adalah ilmu yang berhubungan erat dengan semua aspek kehidupan manusia. Dalam kegiatan sehari-hari, orang selalu berhubungan dengan objek desain. Desain juga telah memberikan nilai dan makna bagi kehidupan manusia yang dipandang sebagai solusi dari masalah. Namun, desain tidak selalu menjadi solusi akhir, bahkan tidak jarang menimbulkan masalah baru yang terkait dengan perilaku, perspektif, struktur nilai, dan budaya penggunanya. Desain berkontribusi untuk menyebarkan nilai-nilai global yang memiliki potensi benturan dengan budaya lokal, perubahan, atau bahkan menyingkirkannya. 
Dalam buku ilustrasi ini format desain akan dibuat dengan book paper dengan ukuran $24 \times 16 \mathrm{~cm}$ bentuk portrait. Ukuran tersebut dipilih agar memaksimalkan ilustrasi dalam buku. Kemudian format gambar disesuaikan antara ilustrasi dan materi yang diangkat pada buku. Ilustrasi akan menggunakan warna hitam dengan latar hitam, lalu penulisan mantra dengan menggunakan warna merah, setelah itu sampul berlatar hitam judul putih dengan simbol berwarna merah sebagai penegas yang di dalamnya terdapat pengarang buku serta pembuat buku ilustrasi.

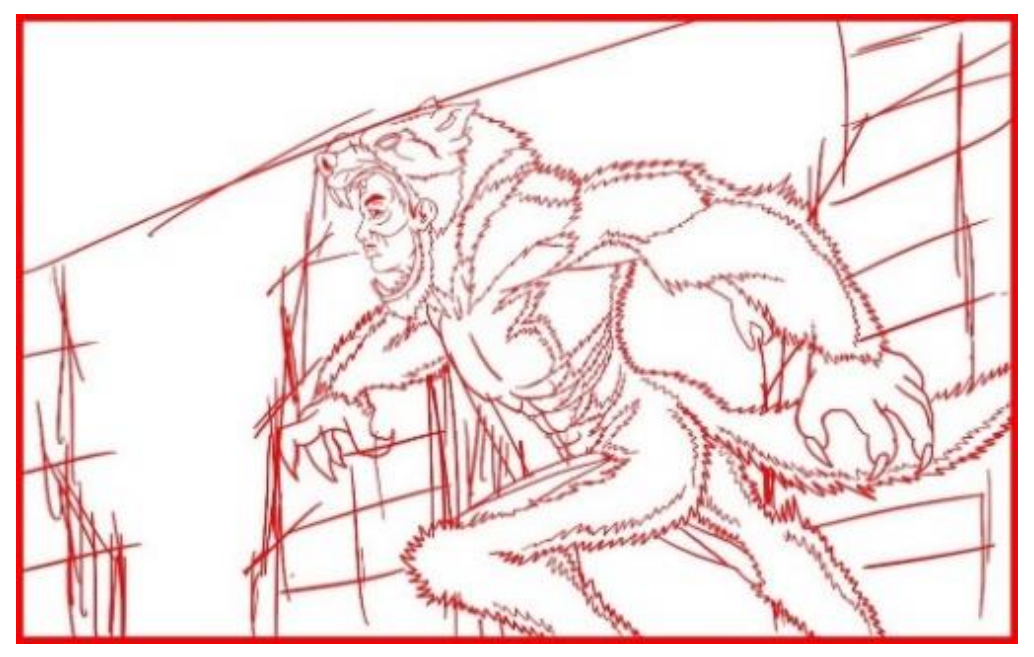

Gambar 3. Sketsa karakter

Sumber: Dokumentasi Penulis (2020)

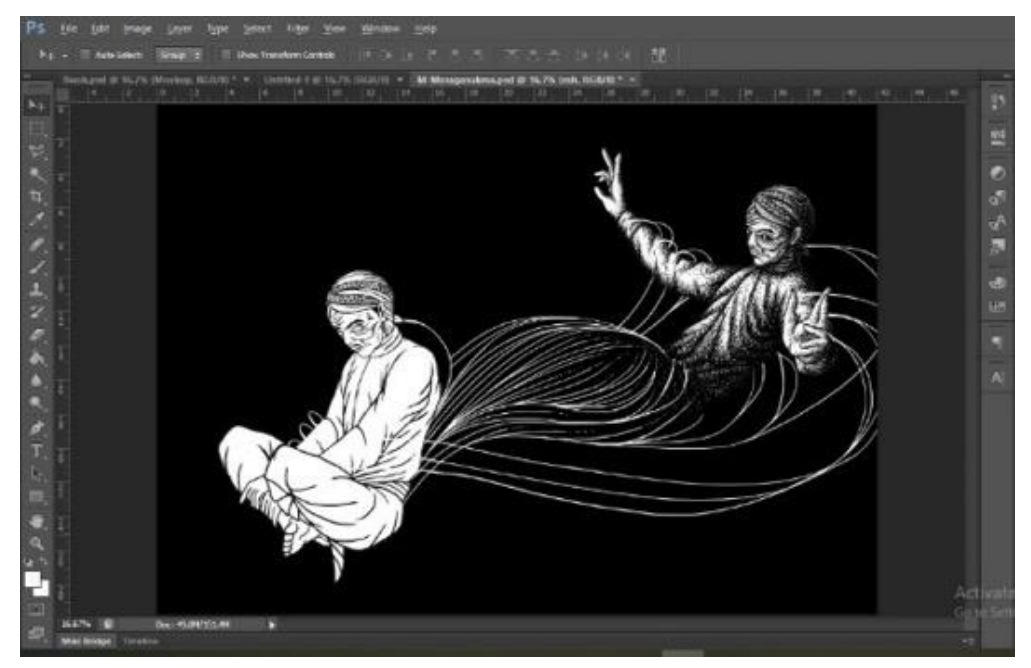

Gambar 4. Proses Arsir Gambar Sumber: Dokumentasi Penulis (2020) 


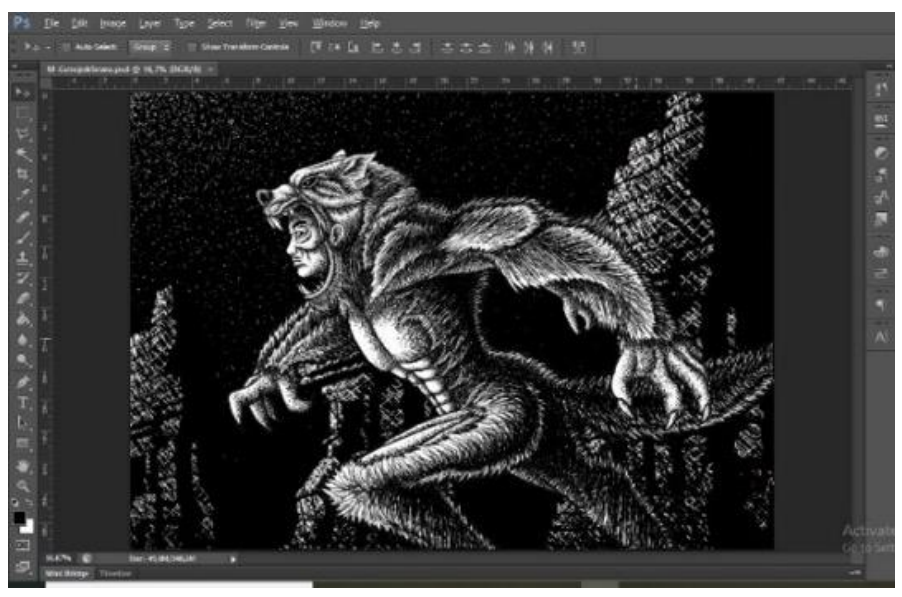

Gambar 5. Proses Detail sebagai Penguat Gambar Sumber: Dokumentasi Penulis (2020)

\section{Konsep Mantra Pada Buku Ilustrasi}

Dalam buku ilustrasi atau media utama dalam perancangan, yaitu penuangan mantra rahasia dikonsepkan dengan pemberian plastik mika dan pada lembar cetakan mantra, sebagai penguat dari mantra rahasia yang dibahas.

\section{Tata Letak}

Tata letak dalam perancangan ini akan menggunakan bantuan gambar ilustrasi dengan teks dan latar belakang serta tokoh Jawa pada ilustrasi. Sedangkan pola halaman akan menggunakan format buku pada umumnya yaitu sejajar pinggir kanan dan kiri dengan mengikuti membuka lembar buku ilustrasi, dan dengan cara baca masyarakat Indonesia yaitu dari kiri ke kanan. Dengan konsep ini terdapat perbandingan 50:50 antara ilustrasi dan penjelasan informasi.

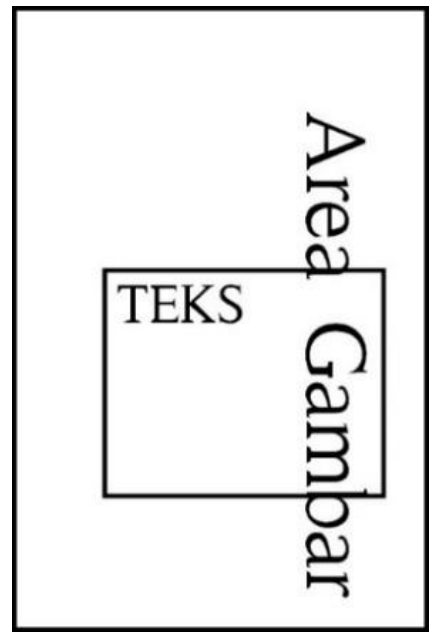

Gambar 6. Tata letak ilustrasi Sumber: Dokumentasi Penulis (2020) 


\section{Tipografi}

Menurut Kurniawan (2014), tipografi adalah suatu kesenian dan teknik memilih dan menata huruf dengan pengaturan penyebarannya pada ruang yang tersedia, untuk menciptakan kesan tertentu, guna kenyamanan membaca semaksimal mungkin.

Font yang digunakan dalam perancangan ini disesuaikan dengan ilustrasi yang akan dibuat dengan tema Jawa kuno dan kesan mistik dari mantra. Hurufnya adalah Birmingham Bold yang dibuat oleh Paul Lloyd pada tahun 2017 dengan gaya retro fancy. Font Birmingham Bold digunakan untuk cover dan sub bab dan body text, font ini bisa di download secara gratis untuk kepentingan pribadi. Penulis memilih font ini dikarenakan berkaitan dan serasi dengan mantra yang dibahas.

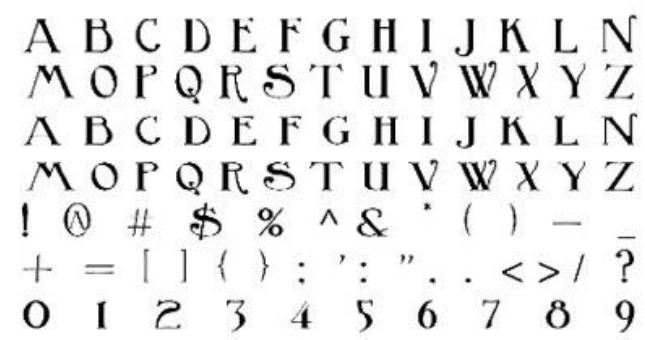

Gambar 7. Font Birmingham Bold

Sumber: Dokumentasi Penulis (2020)

Sedangkan font untuk body text utama menggunakan font Victoria Serif yang dibuat oleh Tipografia Vittoria pada 2018 tema authors. Akan tetapi font Victoria Serif pula digunakan untuk cover, sub bab dan body text disesuaikan dengan kebutuhan buku. Kemudian penulis memilih font ini dikarenakan kebutuhan dari pembaca agar lebih jelas terbaca dan tidak mengurangi buku informasi yang diharapkan.

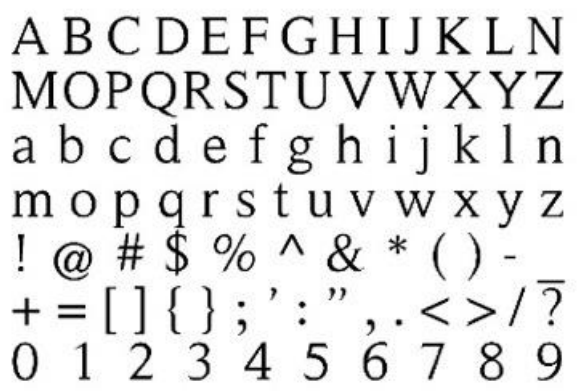

Gambar 8. Font Victoria Serif Sumber: Dokumentasi Penulis (2020) 
Untuk penulisan font Jawa, sebagai penguat dari pengungkapan tanah Jawa, digunakan font aksara Jawa dari font Hanacaraka. Font digunakan untuk cover buku dan notebook serta beberapa desain media pendukung. Font ini memang sudah pasti digunakan agar tidak mengurangi nuansa Jawa yang ada.

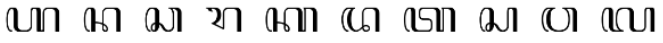 \\ ha na ca ra ka da ta sa wa la

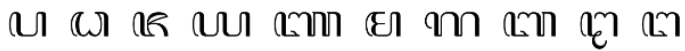 \\ pa dha ja ya nya ma ga ba tha nga \\ Gambar 9. Font Hanacaraka \\ Sumber: https://upload.wikimedia.org/wikipedia/commons/thumb/3/35/Hanacaraka- \\ jawa.svg/1280px-Hanacaraka-jawa.svg.png \\ (diakses pada 15 Januari 2019)
}

Demikian beberapa font yang dipilih dalam perancangan buku ilustrasi, pemilihan beberapa font tersebut dikarenakan huruf-huruf tersebut berkaitan dan masuk ke dalam tema yang dibuat di dalam buku ilustrasi Mantra Jawa Kuno, dimulai dari font Birmingham Bold yang memberikan kesan misterius dan seram. Kemudian font Victoria Serif sebagai penguat dalam bacaan-bacaan dalam isi buku yang mudah dibaca, terakhir adalah font Hanacaraka yang menguatkan sisi Jawa dan menguatkan konsep Jawa Kuno.

\title{
Ilustrasi
}

Menurut Soedarso (2009), ilustrasi adalah sebuah kata yang berasal dari bahasa Belanda yaitu ilustratie yang memiliki arti suatu hiasan dengan gambar. Secara terminologi ilustrasi merupakan suatu gambar yang memiliki fungsi sebagai sarana untuk menjelaskan suatu kejadian. Menurut para ahli menyatakan bahwa ilustrasi adalah sebuah gambar yang melukiskan tujuan tertentu seperti contohnya pada cerpen [12]. Ilustrasi pada perancangan ini bertujuan untuk menampilkan gambaran atau karakter pada Mantra Rahasia Jawa Kuno dan suasana mistis di jaman kuno.

\section{1) Studi Karakter}

Studi karakter merupakan pemilihan karakter atau tokoh yang digunakan sebagai bagian dalam alur, terutama untuk penunjang dalam perancangan ini, yaitu sebagai berikut: 

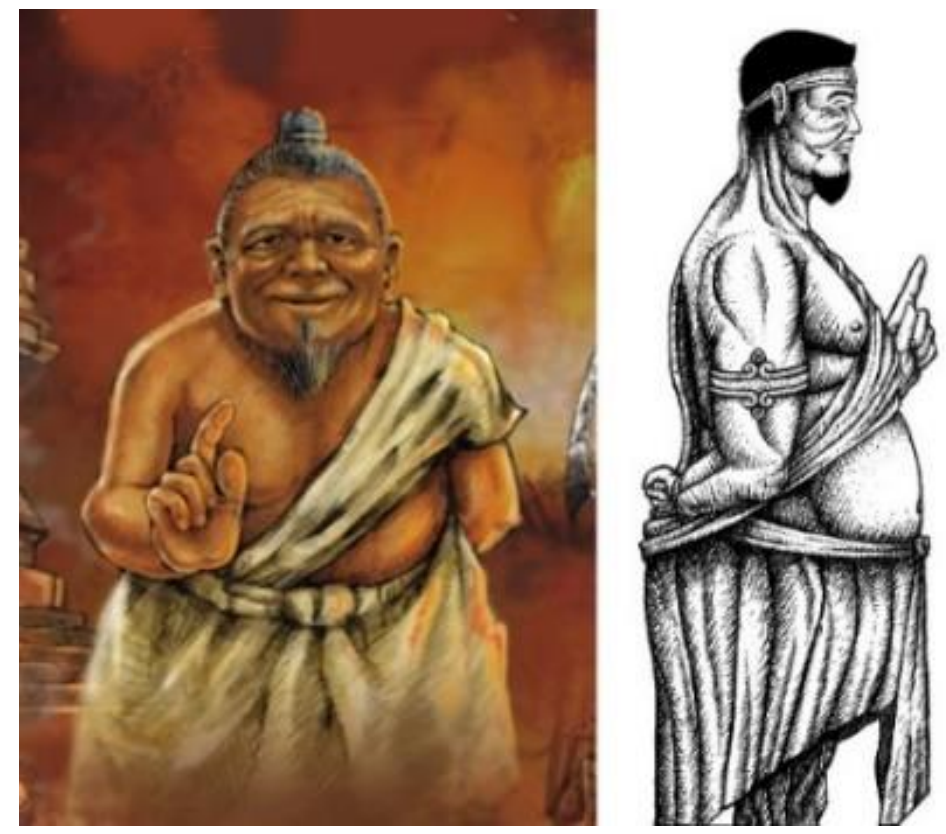

Gambar 10. Ilustrasi Sabdo Palon

Sumber: httpbagusharun.blogspot.com201209jejak-brawijaya-v-sunan-lawu.html

(diakses pada 29 November 2019)
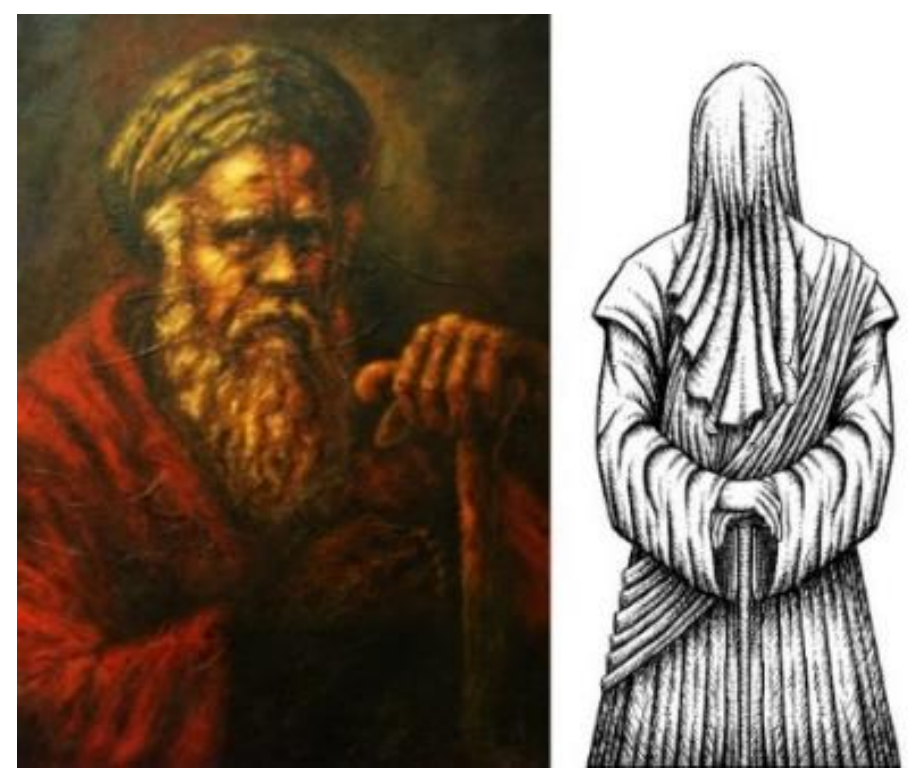

Gambar 11. Ilustrasi Syekh Siti Jenar Sumber:

httpswww.bing.comimagessearchview=detailV2\&id=4BF0A4A754E71056E34659BA50B107E35 D551786\&thid=OIP.v7lfsk-

aIEOTabdHAY1IUAHaJ4\&mediaurl=http\%3A\%2F\%2F4.bp.blogspot.com\%2F-6ZKJ9z1aEQ\%2FUWeGLUVbE8I\%2FAAAAAAAAD8s\%2FVDjWDTQhwaQ\%2Fs160 (diakses pada 29 November 2019) 


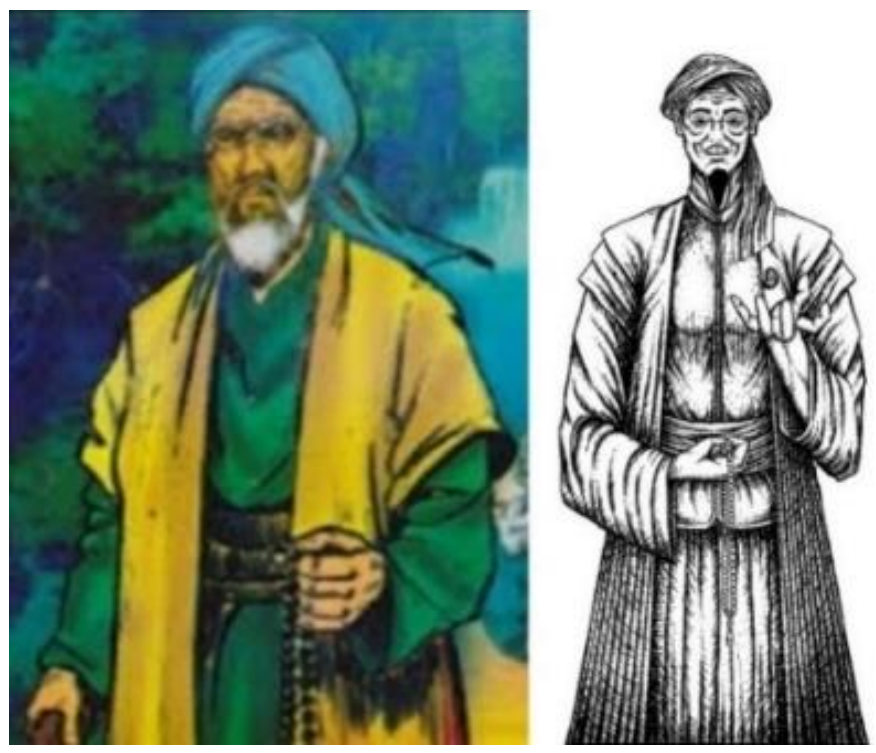

Gambar 12. Ilustrasi Syekh Subakir Sumber:

httpswww.bing.comimagessearchview=detailV2\&id=59E3DD96FC453C11D474AA577A87ED1 F777A26E8\&thid=OIP.C7gPtX91MknR3 YBga8zzDgAAAA\&mediaurl=https\%3A\%2F\%2F2.bp. blogspot.com\%2F-

Xa6awcaiw18\%2FXEGgKyVEF9I\%2FAAAAAAAABXA\%2FVEyYqQ6FfTIW69lEP (diakses pada 29 November 2019)

\section{2) Studi Latar (Background)}

Studi latar merupakan unsur dasar dari sebuah gambar. Dalam desain sederhana maupun lebih rumit, latar belakang melengkapi dan membuat objek di latar menjadi lebih menonjol serta menarik. Dalam perancangan ini penulis membuat studi latar dengan tetap sama dengan mistik yang ada pada gambar ilustrasi.
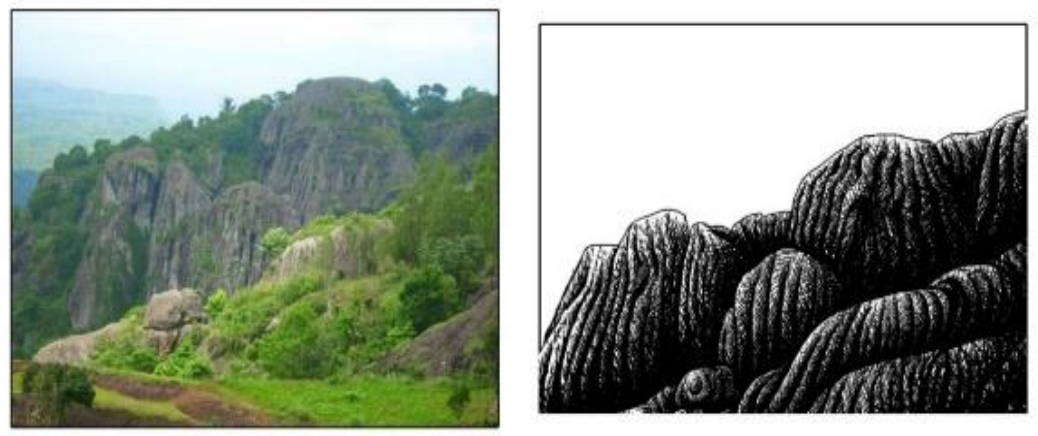

Gambar 13. Latar Pegunungan

Sumber:https://fajar.co.id/2018/10/06/track-ekonomi-menjanjikan-ugg-gunung-sewu/ (diakses pada 29 November 2019) 

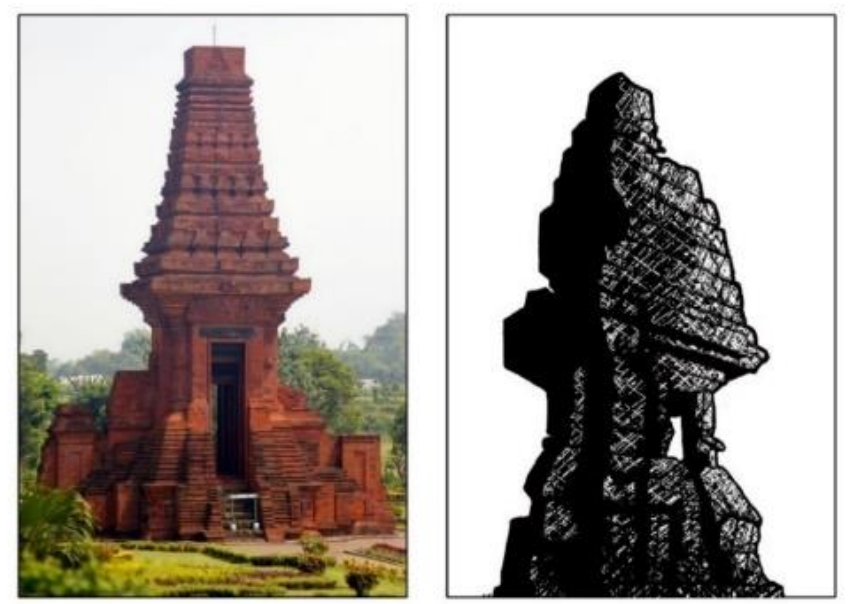

Gambar 14. Latar Kerajaan

Sumber:https://www.ilmusiana.com/2019/02/peninggalan-kerajaan-majapahit.html

(diakses pada 29 November 2019)

\section{Warna}

Menurut Ilham (2019), warna merupakan spektrum tertentu yang terdapat di dalam suatu cahaya sempurna (berwarna putih). Identitas suatu warna ditentukan oleh panjang gelombang dari cahaya tersebut. Sedangkan panjang gelombang warna yang bisa ditangkap oleh mata manusia diantaranya adalah 380 hingga 780 nanometer.

Newton melakukan percobaan dan menyimpulkan, apabila dilakukan pemecahan warna spektrum dari sinar matahari, akan ditemukan warna-warna yang beraneka ragam yang terdiri dari merah, jingga, kuning, hijau, biru, ungu. Warna-warna tersebut dapat kita lihat pada pelangi. Warna yang digunakan dalam karakter dengan pemilihan warna hitam dan putih. Dengan warna tersebut diharapkan dapat mempermudah khalayak sasaran untuk mendapatkan unsur misteri dari gambar atau karakter. Sedangkan untuk cover dan penulisan mantra rahasia, digunakan warna tambahan yaitu merah. Untuk memperkuat konsep dark art yang digunakan oleh penulis.
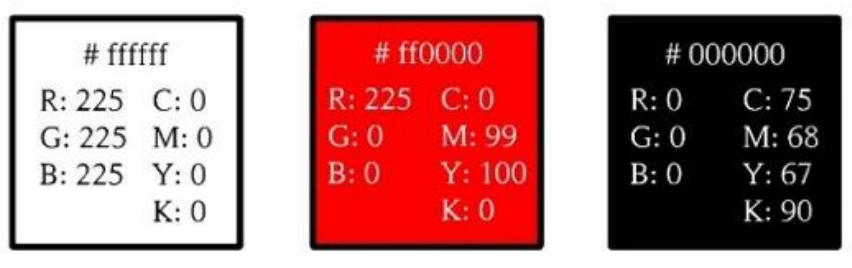

Gambar 15. Konsep Warna untuk Karakter dan Cover Sumber: Dokumentasi Penulis (2020) 
Arti dari warna-warna yang dipilih adalah putih (mencerminkan spiritualitas, kesucian, dan ke Tuhanan), merah (menggambarkan kesan misterius dari mantra), sedangkan hitam (menggambarkan kesan gelap, menampilkan sisi dark art, dan penguat sisi mistis).

\section{KESIMPULAN}

Dari hasil observasi dan wawancara secara langsung dapat disimpulkan bahwa pada dasarnya mantra adalah sebuah do'a atau pepujian, mantra merupakan hal yang baik jika dilakukan dengan baik dan pada hal baik pula. Mantra adalah sebuah nilai budaya yang dimiliki oleh seluruh masyarakat Jawa dan terus menjadi adat istiadat yang diturunkan pada generasi selanjutnya. Fenomena mantra rahasia Jawa kuno yang masih digunakan oleh masyarakat kini menjadi sangat rancu, dikarenakan tidak didukung oleh ilmu yang mumpuni. Sehingga penggunaannya yang tidak sesuai aturan dan disalahgunakan. Oleh karena itu pentingnya informasi dan tata cara yang benar dalam pembacaan mantra, juga sejarah mengenai mantra rahasia sangat dibutuhkan, agar tidak ada lagi penyalahgunaan dalam pembacaan mantra rahasia Jawa kuno. Dengan begitu, diharapkan informasi sejarah budaya mengenai mantra rahasia Jawa kuno dapat menambah ilmu bagi generasi yang ingin mengetahui mantra ataupun generasi selanjutnya yang akan melestarikan adat istiadat tersebut. Segala hal yang masih tabu dapat dibuktikan kebenarannya. Dengan begitu baik tua ataupun muda dapat sama-sama menjaga dan melestarikan budaya apapun yang ada di Indonesia ini.

\section{DAFTAR PUSTAKA}

Akh3ru. (2012). Seni Dark Art Gothic. [Daring]. Tersedia di: http://akh3ru.blogspot.com/2012/09/dark-art-grunge.html, diakses 20 Mei 2020.

Alisjahbana, S. T. (1952). MALAYA Culture halaman 92. [Daring]. Tersedia di: http://www.malaya.or.id/index.php/2015/12/09/mantra-dalam-sastra-indonesialama/

Herususanto, B. (2008). Konsepsi Spritual Leluhur Jawa. Yogjakarta: Katalog dalam Terbitan (KDT).

Ilham, M. (2019). Pengertian Warna. [Daring]. Tersedia di: https://materibelajar.co.id/pengertian-warna/

Kasmana, K. (2009). Citra dan Selera pada Gaya Berbusana Darso. Visualita, vol. 1, no. 1, pp. 19-29, Aug. 2009.

Kurniawan, A. (2014). Pengertian Tipografi. [Daring]. Tersedia di: https://www.gurupendidikan.co.id/pengertian-tipografi/

Kurniawan, I. (2009). DESAIN DAN PERUBAHAN BUDAYA MASYARAKAT. Visualita Jurnal Online Desain Komunikasi Visual, 1(1), 30-34. https://doi.org/10.33375/vslt.v1i1.1090 
Morrisey. (2011). Strategi Perancangan. [Daring]. Tersedia di: https://elib.unikom.ac.id/files/disk1/607/jbptunikompp-gdl-erpinamari-30316-11unikom_e-i.pdf

Pann. (2019). Pengertian Mandatory. [Daring]. Tersedia di: https://glosarium.org/artimandatory/

Riduwan. (2004). Pengertian Metode Observasi Definisi Menurut Para Ahli Dalam Penelitian [Daring]. Tersedia di: http://www.sarjanaku.com/2013/04/pengertianmetode-observasi-definisi.html.

Riyono, A. (2009). Fungsi Mantra. [Daring]. Tersedia di: http://ahdiriyono.blogspot.com/2013/02/22

Salamadian. (2017). 13 Arti Warna dan Psikologi Warna, Terlengkap! (Merah, Ungu, Kuning, Hijau, Cokelat, Biru dll). [Daring]. Tersedia di: https://salamadian.com/artiwarna/

Soedarso. (2009). Pengertian Ilustrasi, Fungsi, Tujuan, Jenis dan Contoh. 2019. [Daring]. Tersedia di: https://jagad.id/pengertian-ilustrasi-fungsi-tujuan-jenis-dan-contoh/

Wijoyo. (2019). Mengenal mantra adat istiadat di kerajaan Ngayogyakarta. Museum Kareta Ngayogyakarta. Yogjakarta. 